\title{
Long term follow up and retrospective study on 533 gastric cancer cases
}

\author{
Wei-Juan Zeng ${ }^{1}$, Wen-Qin Hu², Lin-Wei Wang ${ }^{1}$, Shu-Guang Yan² ${ }^{2}$ Jian-Ding Li3 ${ }^{3}$, Hao-Liang Zhao ${ }^{4}$, Chun-Wei Peng ${ }^{1}$,
} Gui-Fang Yang ${ }^{1}$ and Yan $\mathrm{Li}^{1^{*}}$

\begin{abstract}
Background: Gastric cancer (GC) is the third leading cause of cancer death in China and the outcome of GC patients is poor. The aim of the research is to study the prognostic factors of gastric cancer patients who had curative intent or palliative resection, completed clinical database and follow-up.

Methods: This retrospective study analyzed 533 GC patients from three tertiary referral teaching hospitals from January 2004 to December 2010 who had curative intent or palliative resection, complete clinical database and follow-up information. The GC-specific overall survival (OS) status was determined by the Kaplan-Meier method, and univariate analysis was conducted to identify possible factors for survival. Multivariate analysis using the Cox proportional hazard model and a forward regression procedure was conducted to define independent prognostic factors.

Results: By the last follow-up, the median follow-up time of 533 GC patients was 38.6 mo (range 6.9-100.9 mo), and the median GC-specific OS was $25.3 \mathrm{mo}$ (95\% Cl: 23.1-27.4 mo). The estimated 1-, 2-, 3- and 5-year GC-specific OS rates were $78.4 \%, 61.4 \%, 53.3 \%$ and $48.4 \%$, respectively. Univariate analysis identified the following prognostic factors: hospital, age, gender, cancer site, surgery type, resection type, other organ resection, HIPEC, LN status, tumor invasion, distant metastases, TNM stage, postoperative SAE, systemic chemotherapy and IP chemotherapy. In multivariate analysis, seven factors were identified as independent prognostic factors for long term survival, including resection type, HIPEC, LN status, tumor invasion, distant metastases, postoperative SAE and systemic chemotherapy.
\end{abstract}

Conclusions: Resection type, HIPEC, postoperative SAE and systemic chemotherapy are four independent prognostic factors that could be intervened for GC patients for improving survival.

Keywords: Gastric cancer, GC-specific overall survival, Prognosis, Multivariate analysis, Clinical pathological factors

\section{Background}

Gastric cancer (GC) remains the second leading cause of cancer death worldwide [1], accounting for $8 \%$ of the total cases and $10 \%$ of total deaths in 2008 [2]. In China, GC is the third leading cause of cancer death [3] and the outcome of GC patients is poor, especially for patients at advanced stage, and the 5 -year survival rate is less than $20 \%-25 \%[4]$.

\footnotetext{
*Correspondence: cjr.jianding@vip.163.com; liyansd2@163.com

${ }^{3}$ Department of Medical Imaging, The First Affiliated Hospital of Shanxi Medical University, No 85, South Jiefang Road, Taiyuan City 030001, Shangxi Province, China

'Departments of Oncology \& Pathology, Zhongnan Hospital of Wuhan University, Hubei Key Laboratory of Tumor Biological Behaviors \& Hubei Cancer Clinical Study Center, Wuhan 430071, China

Full list of author information is available at the end of the article
}

Early diagnosis and early treatment remain the best strategy for GC. In China, however, a majority of GC patients are not early cancer by the time when they seek medical attention $[5,6]$. Therefore, surgery-based multidisciplinary treatment approach is warranted in order to improve both overall survival (OS) and the quality of life.

Despite this common-sense knowledge, there is no commonly accepted multidisciplinary treatment strategy in China, primarily due to the lack of large database information reflecting the clinical reality of the current treatment situation.

In our previous studies on GC patients, we evaluated the common tumor markers for the diagnosis of gastric cancer. In these relatively large cohort studies, stage III and beyond patients accounted for over $65 \%$ of the entire patient population [6,7], a result similar to other

\section{Biomed Central}

(c) 2014 Zeng et al.; licensee BioMed Central Ltd. This is an Open Access article distributed under the terms of the Creative Commons Attribution License (http://creativecommons.org/licenses/by/2.0), which permits unrestricted use, distribution, and reproduction in any medium, provided the original work is properly credited. 
reports from China [5,8]. For these patients, GC is no longer a local disease, but at least a regional or a systemic disease.

Currently, surgery remains the most effective therapy for GC, offering an excellent chance (90\%) of a cure for early GC patients [9]. Surgical procedures have a big impact on OS and recurrence [10]. R0 resection with D2 lymphadenectomy is regarded as the standard surgical technique [11,12], as D2 lymphadenectomy had lower recurrence and GC-related death rates [13]. However, for stage III and beyond patients, the currently adopted surgical procedure only removes local tumor mass but often neglects the micro-metastases. Therefore, additional adjuvant therapies are required to ensure better treatment efficacy.

Over the past years, our database has grown bigger and more detailed information on major clinico-pathological characteristics has been accumulated. Therefore, we conducted this comprehensive analysis of the data collected from three major teaching hospitals in Central China, so as to gain deeper insights to the major features of GC in central China and to identify independent factors for prognosis that could be intervened.

\section{Methods}

\section{Ethics statement}

All patients provided written informed consent for their information to be stored in the hospital database; and we obtained separate consent for research. Study approval was obtained from independent ethics committees from Zhongnan Hospital of Wuhan University. The study was undertaken in accordance with the ethical standards of the World Medical Association Declaration of Helsinki.

\section{Patients}

This study included a total of 533 GC patients from three tertiary referral hospitals, from January 2004 to December 2010. These patients underwent resection with curative intent (D2 lymphadenectomy) or palliative resection. All the detailed clinic-pathological information was available, including demographic variables, underlying co-morbidities, surgical modality, lab and image study information, pathological reports, pre- and post-operative therapies, and follow-up information. Pathological information was mainly focused on tumor type, pathological grading, TNM stages, blood vessel or neural invasions. The pathologic staging was based on the 7th edition of AJCC staging criteria [14]. Postoperative treatments were focused on chemotherapy regimens and cycles, and radiotherapy if applicable. GC patients with $\mathrm{T} 2$ or higher, any $\mathrm{N}$ tumors should receive systemic chemotherapy except patients who declined the offer [15]. Hyperthermic intraperitoneal chemotherapy (HIPEC) and intraperitoneal chemotherapy
(IP chemotherapy) were adjuvant chemotherapy, and only those who had peritoneal carcinomatosis (PC) should receive [16]. In our study, the systemic chemotherapy administered were mainly FOLFOX4 and FOLFOX6, HIPEC were mainly using lobaplatin and paclitaxel, and IP chemotherapy were docetaxel and carboplatin.

These patients were followed-up every 3 months during the first 2 years after operation, every 6 months on the third postoperative year and every year thereafter. All the follow-up information was incorporated into a standardized database.

\section{Database construction}

The above-mentioned information was incorporated into a central database, set up at the Zhongnan Hospital of Wuhan University, which undergoes regular updating every 3 months.

\section{Statistical analysis}

All eligibility cases from the central database were analyzed by SPSS 17.0 statistical package software (SPSS Inc., Chicago, IL, USA). The variables were hospital (Zhongnan Hospital, Heji Hospital or Hubei Tumor Hospital), gender (male or female), age ( $\leq 65 \mathrm{yr}$ or $>65 \mathrm{yr}$ ), cancer site (upper third [excluding squamous cell carcinoma at gastroesophageal junction], middle third, lower third or whole stomach), pathological type (well or intermediately differentiated adenocarcinoma, poorly differentiated or undifferentiated carcinoma, signet ring cell carcinoma or mucious adenocarcinoma or others), surgery type (proximal gastrectomy, distal gastrectomy or total gastrectomy), resection type (for stomach itself) (palliative resection or curative resection), other organ resection (mainly included liver, spleen, intestines, ovarian, ovarian ducts) $(0,1,2$ or $\geq 3)$, HIPEC (yes or no), lymph node status (LN status) (N0, N1, N2 or N3), tumor invasion (T1, T2, T3, T4a or T4b), distant metastasis (M0 or M1), pathological stage (I, II, IIIA, IIIB, IIIC or IV) [14], postoperative serious adverse event (postoperative SAE) (defined as life threatening events after operation, including gastrointestinal obstruction, anastomotic leakage, and bleeding leading to grade 3 and above anemia, abdominal abscess) (yes or no), systemic chemotherapy (0, 1 to 6 cycles or $>6$ cycles), IP chemotherapy (yes or no), GCspecific overall survival (GC-specific OS, defined as the time interval from first treatment to GC-specific death, with the last follow-up time on May 31, 2012).

The numerical data was analyzed directly. The category data was converted when necessary. The Kaplan-Meier survival curve was used to study the survival status, using log rank test to decipher the statistical significance, which was judged as $P<0.05$ throughout this study.

To work out independent factors for survival, a Cox proportional hazard model was used to first obtain the 
possible factors and then used forward regression procedure to finally identify the independent factors.

\section{Results}

\section{Characteristics of the patients}

A total of 533 patients with GC were recruited from 3 tertiary referral teaching hospitals, including 194 patients from Zhongnan Hospital of Wuhan University, 182 patients from Heji Hospital and 157 patients from Hubei Tumor Hospital. By the time of last follow-up, 278 deaths (52.2\%) occurred, including 126 deaths (64.9\%) out of 194 enrolled patients from Zhongnan Hospital of Wuhan University, 84 deaths (46.2\%) out of 182 enrolled patients from Heji Hospital, and 68 deaths (43.3\%) out of 157 enrolled patients from Hubei Tumor Hospital. The median age of cases was 58 years (range $20-85$ years), and male-to-female ratio was 2.7 to 1 . Detailed information on major demographic and clinico-pathological characteristics was listed in Table 1.

\section{GC-specific OS}

By the time of last follow-up, the median follow-up time was 38.6 mo (range 6.9-100.9 mo), and 278 patients died out of the entire 533 assessable patients (52.2\%). The median GC-specific OS was 25.3 mo (95\% CI: 23.1-27.4 mo). The survival curve by stages was shown in Figure 1. The estimated 1-, 2-, 3- and 5-year GC-specific OS rates were $78.4 \%, 61.4 \%, 53.3 \%$ and $48.4 \%$, respectively. The median survival by stages I, II, IIIA, IIIB, IIIC and IV were $85.2 \mathrm{mo}$ (95\% CI: 76.1-94.3 mo), $53.9 \mathrm{mo}$ (95\% CI: 46.6-61.3 mo), $40.0 \mathrm{mo}$ (95\% CI: 21.7-58.3 mo), $28.0 \mathrm{mo}$ (95\% CI: $14.9-41.1 \mathrm{mo}), 14.8$ mo (95\% CI: $10.6-19.1 \mathrm{mo})$ and 11.1 mo (95\% CI: 9.7-12.4 mo), respectively. As shown in Figure 1, significant differences in GC-specific OS were found among different clinical stages. Patients at clinical stage IIIB and beyond had much poorer GCspecific OS status than other patients.

\section{Mortality analysis}

By the time of last follow-up, 278 patients (52.2\%) died among the entire 533 assessable patients. In terms of absolute number of patient death on the yearly basis, there were 114 (41.0\%), 92 (33.1\%), 43 (15.5\%), 18 (6.5\%), 8 (2.9\%) deaths, respectively, in the 1st, 2ed, 3rd, 4th, and 5 th postoperative year. Only $3(1.1 \%)$ deaths occurred after 5 years. Information on GC-specific death in relationship with clinical stages was depicted in Figure 2. Putting together, there were 249 (89.6\%) deaths within three years after operation.

\section{Univariate survival analysis}

In this study, all variables were analyzed by KaplanMeier curve and log-rank test. Among these variables, pathological type had no statistically significant impact on GC-specific OS $(P=0.212)$, but statistically significant factors were hospital $(P=0.008)$, age $(P<0.001)$, gender $(P=0.019)$, cancer site $(P=0.004)$, surgery type $(P<0.001)$, resection type $(P<0.001)$, other organ resection $(P<0.001)$, HIPEC $(P<0.001)$, LN status $(P<0.001)$, tumor invasion $(P<0.001)$, distant metastases $(P<0.001)$, TNM stage $(P<$ $0.001)$, postoperative SAE $(P<0.001)$, systemic chemotherapy $(P=0.001)$, and IP chemotherapy $(P=0.003)$ (Table 1$)$.

\section{Multivariate survival analysis}

After univariate survival analysis, the above significant factors were further subjected to multivariate analysis using Cox proportional hazard model and forward regression procedure. The following variables were identified as independent factors for prognosis: tumor invasion $(P<0.001)$, LN status $(P<0.001)$, distant metastases $(P<0.001)$, resection type $(P=0.015)$, HIPEC $(P=0.049)$, postoperative SAE $(P<0.001)$ and systemic chemotherapy $(P<0.001)$ (Table 2$)$.

\section{Discussion}

Several important points should be considered from this study. First, a majority of GC patients are at advanced clinical stage. In our series of 533 patients, 354 cases (66.4\%) were clinically stage III and beyond. For these patients, GC is no longer a local disease, but at least a regional or a systemic disease. Although surgery could remove the bulky tumor mass itself, it may leave some unseen cancer cells in the operating field. Therefore, more intensive adjuvant chemotherapy should be followed in order to eradicate these left-over cancer cells. Two large scale randomized clinical trials have already demonstrated the superiority of this approach over conventional surgery alone $[17,18]$. Another reasonable approach is to start perioperative chemotherapy, to down-stage the tumor, followed by curative resection. It has been proven that such a treat modality indeed could improve the clinical outcomes of GC patients [19].

Secondly, our analysis found that over $40 \%$ of GC death occurred in the first year after operation, and another $30 \%$ plus of GC death occurred during the second year after operation [20-22]. Therefore, it is clinically important to design rational strategies to address these problems. One key consideration is that high risk factors should be investigated and identified, so as to reduce them and reduce the death risk. Another strategy is to design a close follow-up plan and strictly implement it, so as to identify those patients with early signs of recurrence and apply appropriate therapies. Among the currently used methods, serum tumor markers study and medical imaging studies are most widely used approaches. Regular monitoring blood tumor markers carcinoembryonic antigen (CEA) and carboxyl antigen 199 (CA19-9) could help provide warning information on cancer recurrence [23]. 
Table 1 Characteristics of the $533 \mathrm{GC}$ patients enrolled into this study

\begin{tabular}{|c|c|c|c|c|}
\hline Variables & Total n (\%) & Events n (\%) & $\begin{array}{l}\text { Median GC-specific } \\
\text { OS }(95 \% \mathrm{Cl})(\mathrm{mo})\end{array}$ & $P$ value \\
\hline \multicolumn{5}{|l|}{ Age (yr) } \\
\hline$\leq 65$ & $380(71.3)$ & $178(46.8)$ & $51.7(39.7-63.7)$ & \multirow{2}{*}{$<0.001$} \\
\hline$>65$ & $153(28.7)$ & $100(65.4)$ & $28.0(21.6-34.4)$ & \\
\hline \multicolumn{5}{|l|}{ Gender } \\
\hline Male & $389(73.0)$ & $192(49.4)$ & $39.7(29.9-49.5)$ & \multirow{2}{*}{0.019} \\
\hline Female & $144(27.0)$ & $86(59.7)$ & $28.0(17.9-38.1)$ & \\
\hline \multicolumn{5}{|l|}{ Cancer site } \\
\hline Upper third & $156(29.3)$ & $80(51.3)$ & $32.6(25.9-39.3)$ & \multirow{4}{*}{0.004} \\
\hline Middle third & $119(22.3)$ & $61(51.3)$ & $38.9(9.4-68.4)$ & \\
\hline Lower third & $222(41.7)$ & $112(50.5)$ & $42.1(34.2-49.9)$ & \\
\hline Whole stomach & $36(6.8)$ & $25(69.4)$ & $13.2(10.1-16.3)$ & \\
\hline \multicolumn{5}{|l|}{ Pathological type } \\
\hline Adeno WD/ID & $131(24.6)$ & $59(45.0)$ & $42.1(29.9-54.2)$ & \multirow{4}{*}{0.212} \\
\hline Adeno PD/UN & $299(56.1)$ & $160(53.5)$ & $34.9(27.5-42.4)$ & \\
\hline Signet ring/mucious Ca & 85 (15.9) & 49 (57.6) & $28.0(10.9-45.1)$ & \\
\hline Others & $18(3.4)$ & $10(55.6)$ & $33.7(20.0-47.5)$ & \\
\hline \multicolumn{5}{|l|}{ Surgery type } \\
\hline Proximal gastrectomy & $169(31.7)$ & $82(48.5)$ & $35.9(20.5-51.3)$ & \multirow{3}{*}{$<0.001$} \\
\hline Distal gastrectomy & $268(50.3)$ & $128(47.8)$ & $46.6(38.1-55.1)$ & \\
\hline Total gastrectomy & $96(18.0)$ & $68(70.8)$ & $17.4(11.3-23.4)$ & \\
\hline \multicolumn{5}{|l|}{ Resection type } \\
\hline Palliative resection & $11(2.1)$ & $11(100.0)$ & $9.8(8.0-11.6)$ & \multirow{2}{*}{$<0.001$} \\
\hline Curative resection & $522(97.9)$ & $267(51.1)$ & $38.9(31.8-46.0)$ & \\
\hline \multicolumn{5}{|l|}{ Other organ resection (n) } \\
\hline 0 & $507(95.1)$ & $256(50.5)$ & $39.3(32.5-46.0)$ & \multirow{4}{*}{$<0.001$} \\
\hline 1 & $14(2.6)$ & $11(78.6)$ & $24.1(9.6-38.7)$ & \\
\hline 2 & $8(1.5)$ & $7(87.5)$ & $12.4(2.7-22.2)$ & \\
\hline$\geq 3$ & $4(0.8)$ & $4(100.0)$ & $13.6(2.7-24.4)$ & \\
\hline \multicolumn{5}{|l|}{ HIPEC } \\
\hline No & $505(94.7)$ & $251(49.7)$ & $39.7(32.4-47.0)$ & \multirow{2}{*}{$<0.001$} \\
\hline Yes & $28(5.3)$ & $27(96.4)$ & $13.4(9.6-17.2)$ & \\
\hline \multicolumn{5}{|l|}{ LN status } \\
\hline No & $172(32.3)$ & $51(29.7)$ & $67.3(59.8-74.8)$ & \multirow{4}{*}{$<0.001$} \\
\hline N1 & $112(21.0)$ & $57(50.9)$ & $35.9(26.8-45.0)$ & \\
\hline N2 & $143(26.8)$ & $86(60.1)$ & $27.0(19.9-34.1)$ & \\
\hline N3 & $106(20.0)$ & $84(30.5)$ & $14.4(12.0-16.8)$ & \\
\hline \multicolumn{5}{|l|}{ Tumor invasion } \\
\hline $\mathrm{T} 1$ & $25(4.7)$ & $3(12.0)$ & $75.4(66.4-84.4)$ & \multirow{5}{*}{$<0.001$} \\
\hline $\mathrm{T} 2$ & $85(15.9)$ & $19(22.4)$ & $72.7(62.2-83.2)$ & \\
\hline T3 & $2(0.4)$ & $1(50.0)$ & $29.1(10.7-47.4)$ & \\
\hline T4a & $332(62.3)$ & $187(56.3)$ & $33.0(26.6-39.4)$ & \\
\hline T4b & $89(16.7)$ & $68(76.4)$ & $14.8(10.8-18.9)$ & \\
\hline
\end{tabular}


Table 1 Characteristics of the 533 GC patients enrolled into this study (Continued)

\begin{tabular}{|c|c|c|c|c|}
\hline \multicolumn{5}{|c|}{ Distant metastases } \\
\hline No & $478(89.7)$ & $224(46.9)$ & $42.5(34.6-50.4)$ & \multirow{2}{*}{$<0.001$} \\
\hline Yes & $55(10.3)$ & $54(98.2)$ & $10.6(9.0-12.1)$ & \\
\hline \multicolumn{5}{|l|}{ TNM staging } \\
\hline Stage I & $79(14.8)$ & $8(10.1)$ & $85.2(76.1-94.3)$ & \multirow{6}{*}{$<0.001$} \\
\hline Stage II & $100(18.8)$ & $35(35.0)$ & $53.9(46.6-61.3)$ & \\
\hline Stage IIIA & $80(15.0)$ & $38(47.5)$ & $40.0(21.7-58.3)$ & \\
\hline Stage IIIB & $116(21.8)$ & $67(57.8)$ & $28.0(14.9-41.1)$ & \\
\hline Stage IIIC & $117(22.0)$ & $90(76.9)$ & $14.8(10.6-19.1)$ & \\
\hline Stage IV & $41(7.7)$ & $40(97.6)$ & $11.1(9.7-12.4)$ & \\
\hline \multicolumn{5}{|c|}{ Postoperative SAE } \\
\hline No & $458(85.9)$ & $205(44.8)$ & $49.8(32.5-67.0)$ & \multirow{2}{*}{$<0.001$} \\
\hline Yes & $75(14.1)$ & $73(97.3)$ & $14.8(10.0-19.6)$ & \\
\hline \multicolumn{5}{|c|}{ Systemic chemotherapy (cycles) } \\
\hline 0 & $217(40.7)$ & $128(59.0)$ & $26.3(19.2-33.4)$ & \multirow{3}{*}{0.001} \\
\hline 1 to 6 & $302(56.7)$ & $142(47.0)$ & $51.7(36.6-66.9)$ & \\
\hline$>6$ & $14(2.6)$ & $8(57.1)$ & $37.8(16.9-58.7)$ & \\
\hline \multicolumn{5}{|c|}{ IP chemotherapy } \\
\hline No & $521(97.7)$ & $267(51.2)$ & $37.0(29.8-44.2)$ & \multirow{2}{*}{0.003} \\
\hline Yes & $12(2.3)$ & $11(91.7)$ & $11.1(7.0-15.1)$ & \\
\hline
\end{tabular}

GC: gastric cancer; GC-specific OS: gastric cancer-specific overall survival; Adeno WD/ID: well differentiated or intermediately differentiated adenocarcinoma; Adeno PD/UN: poorly differentiated or undifferentiated carinoma; Signet ring/mucious Ca: Signet ring cell carcinoma or mucious adenocarcinoma; HIPEC: hyperthermic intraperitoneal chemotherapy; LN status: lymph node status; SAE: serious adverse event; IP chemotherapy: intraperitoneal chemotherapy.

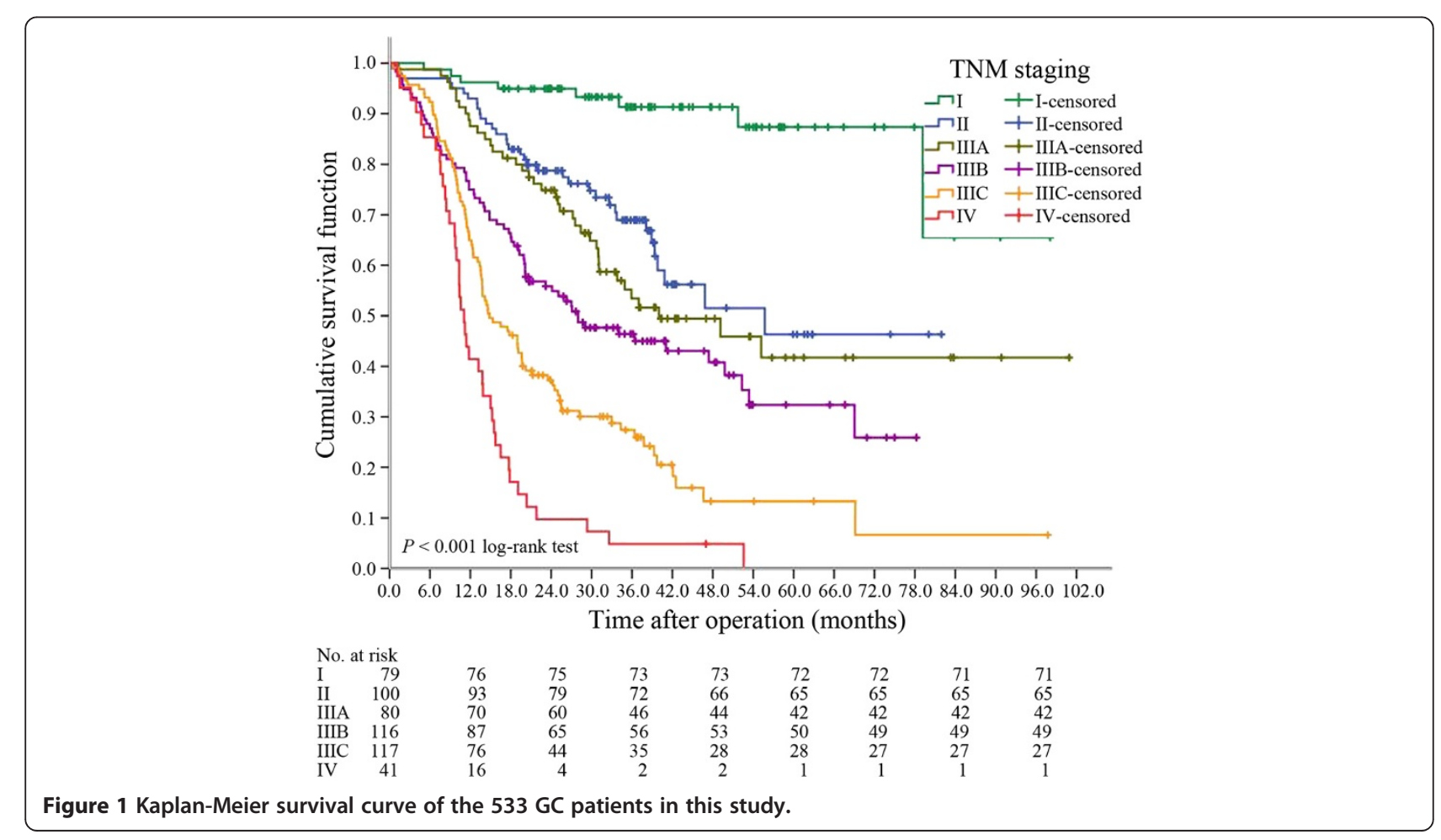




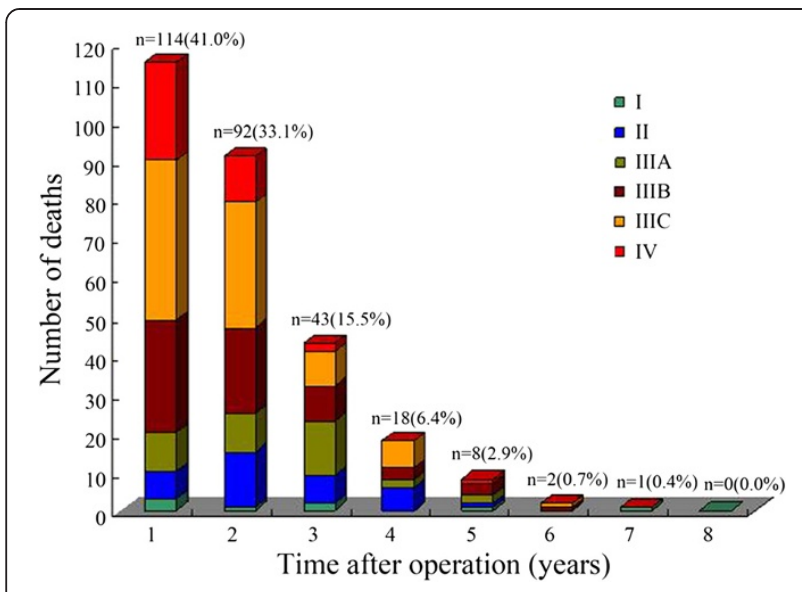

Figure 2 Information on GC-specific deaths in relationship with clinical stages.

Various clinicopathological factors have been reported to impact on GC-specific OS, such as age, gender, cancer site, surgery type, resection type, other organ resection, HIPEC, LN status, tumor invasion, distant metastases, TNM stage, postoperative SAE, systemic chemotherapy and IP chemotherapy $[5,7,8,20,24-28]$. These results are in accordance with our study. In our study, pathological type had no impact on GC-specific OS, which is not in conformity with several previous studies that concluded that pathological type was an important factor for prognosis and survival of GC $[5,24]$, but is in agreement with some other studies that reported that pathological type had no influence on GCspecific OS $[7,27]$. This could be due to the different typing method used. It has been documented that Lauren histological classification is a simple and practical typing method to have significant correlation with survival of GC. Clinicalpathological information of this study was obtained from hospital department of pathology, and they did not adopt Lauren classification. In future studies, we should adopt this classification.

Table 2 Independent prognostic factors of 533 GC patients identified by multivariate analysis

\begin{tabular}{llllll}
\hline Covariate & $\mathbf{X}^{\mathbf{2}}$ & $P$ & HR & \multicolumn{2}{c}{$95 \% \mathrm{Cl}$} \\
\cline { 5 - 6 } & & & & Lower & Upper \\
\hline Tumor invasion & 13.008 & $<0.001$ & 1.022 & 1.010 & 1.034 \\
LN status & 36.845 & $<0.001$ & 1.462 & 1.293 & 1.653 \\
Distant metastases & 29.004 & $<0.001$ & 2.832 & 1.939 & 4.137 \\
Resection type & 5.900 & 0.015 & 0.430 & 0.218 & 0.850 \\
HIPEC & 3.863 & 0.049 & 1.707 & 1.001 & 2.910 \\
Postoperative SAE & 27.752 & $<0.001$ & 2.507 & 1.781 & 3.528 \\
Systemic chemotherapy & 24.064 & $<0.001$ & 0.521 & 0.402 & 0.676 \\
\hline
\end{tabular}

GC: gastric cancer; HR: hazard ratio; Cl: confidence interval; LN status: lymph node status; HIPEC: hyperthermic intraperitoneal chemotherapy; SAE: serious adverse event.
For cancer patients, the clinical outcomes depend on several important factors, which could be divided into those that cannot be intervened such as TNM stage, and those can be intervened such as treatment models. After the Cox proportional hazard model analysis, we worked out seven independent factors that had significant impact on survival, six of these seven factors have already been well recognized as the most important determinants of patients' survival $[5,7,8,29]$. What deserves special attention is the finding that HIPEC is also an independent factor for improved survival. Several phases I to III studies have already demonstrated the treatment advantage of HIPEC. Glehen et al. consecutively treated 49 advanced GC patients with HIPEC, which resulted in 10.3 months of GC-specific OS, against 6.1 months of GC-specific OS treated with only standard curative resection [30]. In another study by Yonemura et al., 107 GC patients also treated with HIPEC, and the GC-specific OS was 11.5 months [31]. More importantly, a recent phase III prospective randomized clinical trial also confirmed the survival advantage of 11.0 months in the HIPEC group against 6.5 months in the CRS group [32]. In addition, a systematic review and meta-analysis of 13 acceptable qualities randomized controlled trials also have established that HIPEC has significant survival advantage over the currently standard treatment for advanced GC [33]. Taken together, all these facts confirm the value of HIPEC for the treatment of stage III and beyond GC patients. In this study, the median survival of patients with HIPEC was 13.4 mo (95\% CI: 9.6-17.2), which was shorter than others without HIPEC (39.7 mo [95\% CI: 32.4-47.0]). It was due to patients with HIPEC were gastric cancer with metastasis and prognosis was not optimistic. However, the median survival of patients with HIPEC was longer than patients with metastasis (13.4 mo vs 10.6 mo, $P<0.05$ ). It supports HIPEC has significant survival advantage even though there could be selection bias in this regard, due to the limited number of patients treated by HIPEC.

Postoperative SAE included gastrointestinal obstruction, anastomotic leakage, and bleeding leading to grade 3 and above anemia, abdominal abscess. All these have been confirmed to have a significant negative impact on GC-specific OS. In the study of Sierzega et al. [34], the median OS of patients with anastomotic leakage was significantly lower than patients with non-anastomotic leakage (4.1 mo vs. $23 \mathrm{mo}, P<0.001$ ), and the progression-free survival of patients with anastomotic leakage was also significantly shorter than patients with non-anastomotic leakage (11 mo vs. 19 mo, $P=0.021$ ). In another study by Yoo et al. [35], the mean OS of patients with anastomotic leakage was significantly lower than patients with non-anastomotic leakage (30.5 mo vs. 96.2 mo, $P<0.001)$. Anastomotic leakage could promote gastric cancer progression by prolonging inflammation [34-36]. According to Tokunaga et al. [37], GC 
patients with intra-abdominal infection had a poorer 5 -year OS rate and 5-relapse-free survival rate than patients without intra-abdominal infectins $(66.4 \%$ vs. $86.8 \%, P<0.001$ and $64.9 \%$ vs. $84.5 \%, P<0.001)$. In another study by Li et al. [38], postoperative complications including gastrointestinal obstruction, anastomotic leakage, and bleeding leading and abdominal abscess all were independent and negative prognostic factors for GC. Therefore, all efforts should be made to reduce the risk for postoperative SAE, including careful patient selection for surgery and optimized perioperative patient care.

\section{Conclusion}

In summary, this study identified four independent prognostic factors that could be intervened for GC patients, including curative resection, HIPEC, postoperative SAE and systemic chemotherapy, and three independent prognostic factors that cannot be intervened: tumor invasion, LN status and distant metastasis. Therefore, increasing attention should be directed at better understanding tumor biology involved in cancer invasion and metastasis, and refining multi-disciplinary comprehensive treatment strategies to enhance efficacy and reduce SAE.

\section{Competing interests}

The authors declare that they have no competing interests.

\section{Authors' contributions}

YL, GFY and JDL conceived of the study, and participated in its design and coordination. WQH, LWW, SGY, HLZ, CWP and WJZ participated in the database collection and follow-up. WJZ performed the statistical analyses and drafted the manuscript. All authors read and approved the final manuscript.

\section{Acknowledgements \\ This work is supported by Award for Excellent PhD. Candidates Funded by Ministry of Education of China (No. 5052011303014), Science Fund of the National Natural Science Foundation of China (No. 81171396), Science Fund for Creative Research Groups of the National Natural Science Foundation of China (No. 20621502, 20921062), and the Fundamental Research Funds for the Central Universities of Ministry of Education of China (No. 4103005).}

\section{Author details \\ 'Departments of Oncology \& Pathology, Zhongnan Hospital of Wuhan University, Hubei Key Laboratory of Tumor Biological Behaviors \& Hubei Cancer Clinical Study Center, Wuhan 430071, China. ${ }^{2}$ Department of Surgery, Heji Hospital Affiliated to Changzhi Medical College, Changzhi 046000, China. ${ }^{3}$ Department of Medical Imaging, The First Affiliated Hospital of Shanxi Medical University, No 85, South Jiefang Road, Taiyuan City 030001, Shangxi Province, China. ${ }^{4}$ Department of General Surgery, Shanxi University Hospital, No 99, Longcheng Street, Taiyuan City 046000, Shangxi Province, China.}

Received: 2 December 2012 Accepted: 8 May 2014

Published: 16 May 2014

\section{References}

1. Ferlay J, Shin HR, Bray F, Forman D, Mathers C, Parkin DM: Estimates of worldwide burden of cancer in, GLOBOCAN 2008. Int I Cancer 2008, 2010(127):2893-2917.

2. Jemal A, Bray F, Center MM, Ferlay J, Ward E, Forman D: Global cancer statistics. CA Cancer J Clin 2011, 61:69-90.

3. Yang L: Incidence and mortality of gastric cancer in China. World J Gastroenterol 2006, 12:17-20.
4. Hartgrink HH, Jansen EP, van Grieken NC, van de Velde CJ: Gastric cancer. Lancet 2009, 374:477-490.

5. Wang W, Sun XW, Li CF, Lv L, Li YF, Chen YB, Xu DZ, Kesari R, Huang CY, Li W, Zhan YQ, Zhou ZW: Comparison of the 6th and 7th editions of the UICC TNM staging system for gastric cancer: results of a Chinese singleinstitution study of 1,503 patients. Ann Surg Oncol 2011, 18:1060-1067.

6. Chen C, Chen LQ, Chen LD, Yang GL, Li Y: Evaluation of tumor markers biochip $\mathrm{C} 12$ system in the diagnosis of gastric cancer and the strategies for improvement: analysis of 100 cases. Hepatogastroenterology 2008, 55:991-997.

7. Wu HL, Tian Q, Peng CW, Liu SP, Li Y: Multivariate survival and outcome analysis of 154 patients with gastric cancer at a single Chinese institution. Asian Pac J Cancer Prev 2011, 12:3341-3345.

8. Zhang XF, Huang CM, Lu HS, Wu XY, Wang C, Guang GX, Zhang JZ, Zheng $\mathrm{CH}$ : Surgical treatment and prognosis of gastric cancer in 2,613 patients. World J Gastroenterol 2004, 10:3405-3408.

9. Li BS, Zhao YL, Guo G, Li W, Zhu ED, Luo X, Mao XH, Zou QM, Yu PW, Zuo QF, Li N, Tang B, Liu KY, Xiao B: Plasma microRNAs, miR-223, miR-21 and miR-218, as novel potential biomarkers for gastric cancer detection. PLoS One 2012, 7:e41629.

10. Yokota T, Ishiyama S, Saito T, Teshima S, Shimotsuma M, Yamauchi H: Treatment strategy of limited surgery in the treatment guidelines for gastric cancer in Japan. Lancet Oncol 2003, 4:423-428.

11. Diaz DLA, Yarnoz C, Aguilar R, Artieda C, Ortiz H: Rationale for gastrectomy with D2 lymphadenectomy in the treatment of gastric cancer. Gastric Cancer 2008, 11:96-102.

12. D'Annibale A, Pende V, Pernazza G, Monsellato I, Mazzocchi P, Lucandri G, Morpurgo E, Contardo T, Sovernigo G: Full robotic gastrectomy with extended (D2) lymphadenectomy for gastric cancer: surgical technique and preliminary results. J Surg Res 2011, 166:e113-e120.

13. Songun I, Putter H, Kranenbarg EM, Sasako M, van de Velde CJ: Surgical treatment of gastric cancer: 15-year follow-up results of the randomised nationwide Dutch D1D2 trial. Lancet Oncol 2010, 11:439-449.

14. Washington $\mathrm{K}: 7$ th edition of the AJCC cancer staging manual: stomach. Ann Surg Oncol 2010, 17:3077-3079.

15. Ajani JA, Bentrem DJ, Besh S, D'Amico TA, Das P, Denlinger C, Fakih MG, Fuchs CS, Gerdes H, Glasgow RE, Hayman JA, Hofstetter WL, Ilson DH, Keswani RN, Kleinberg LR, Korn WM, Lockhart AC, Meredith K, Mulcahy MF, Orringer MB, Posey JA, Sasson AR, Scott WJ, Strong VE, Varghese TJ, Warren G, Washington MK, Willett C, Wright CD, McMillian NR, et al. Gastric cancer, version 2.2013: featured updates to the NCCN Guidelines. J Natl Compr Canc Netw 2013, 11:531-546.

16. Yonemura Y, Endou Y, Sasaki T, Hirano M, Mizumoto A, Matsuda T, Takao N, Ichinose M, Miura M, Li Y: Surgical treatment for peritoneal carcinomatosis from gastric cancer. Eur J Surg Oncol 2010, 36:1131-1138.

17. Sakuramoto S, Sasako M, Yamaguchi T, Kinoshita T, Fujii M, Nashimoto A, Furukawa H, Nakajima T, Ohashi Y, Imamura H, Higashino M, Yamamura Y, Kurita A, Arai K: Adjuvant chemotherapy for gastric cancer with S-1, an oral fluoropyrimidine. N Engl J Med 2007, 357:1810-1820.

18. Macdonald JS, Smalley SR, Benedetti J, Hundahl SA, Estes NC, Stemmermann GN, Haller DG, Ajani JA, Gunderson LL, Jessup JM, Martenson JA: Chemoradiotherapy after surgery compared with surgery alone for adenocarcinoma of the stomach or gastroesophageal junction. N Engl J Med 2001, 345:725-730.

19. Cunningham D, Allum WH, Stenning SP, Thompson JN, Van de Velde CJ, Nicolson M, Scarffe JH, Lofts FJ, Falk SJ, Iveson TJ, Smith DB, Langley RE, Verma M, Weeden S, Chua YJ, MAGIC TP: Perioperative chemotherapy versus surgery alone for resectable gastroesophageal cancer. $N$ Engl $J$ Med 2006, 355:11-20.

20. Shiraishi N, Inomata M, Osawa N, Yasuda K, Adachi Y, Kitano S: Early and late recurrence after gastrectomy for gastric carcinoma: Univariate and multivariate analyses. Cancer 2000, 89:255-261.

21. Kodera Y, Ito S, Yamamura Y, Mochizuki Y, Fujiwara M, Hibi K, Ito K, Akiyama S, Nakao A: Follow-up surveillance for recurrence after curative gastric cancer surgery lacks survival benefit. Ann Surg Oncol 2003, 10:898-902.

22. Yoo CH, Noh SH, Shin DW, Choi SH, Min JS: Recurrence following curative resection for gastric carcinoma. Br J Surg 2000, 87:236-242.

23. Yang $X Q$, Yan $L$, Chen $C$, Hou JX, Li Y: Application of $\mathrm{C} 12$ multi-tumor marker protein chip in the diagnosis of gastrointestinal cancer: results of 329 surgical patients and suggestions for improvement. Hepatogastroenterology 2009, 56:1388-1394. 
24. Yang D, Hendifar A, Lenz C, Togawa K, Lenz F, Lurje G, Pohl A, Winder T, Ning Y, Groshen S, Lenz HJ: Survival of metastatic gastric cancer: Significance of age, sex and race/ethnicity. J Gastrointest Oncol 2011, 2:77-84.

25. Nanthakumaran S, Fernandes E, Thompson AM, Rapson T, Gilbert FJ, Park KG: Morbidity and mortality rates following gastric cancer surgery and contiguous organ removal, a population based study. Eur J Surg Oncol 2005, 31:1141-1144.

26. Li C, Yan M, Chen J, Xiang M, Zhu ZG, Yin HR, Lin YZ: Surgical resection with hyperthermic intraperitoneal chemotherapy for gastric cancer patients with peritoneal dissemination. J Surg Oncol 2010, 102:361-365.

27. Landry CS, Brock G, Scoggins CR, McMasters KM, Martin RN: A proposed staging system for gastric carcinoid tumors based on an analysis of 1,543 patients. Ann Surg Oncol 2009, 16:51-60.

28. Cheong JH, Shen JY, Song CS, Hyung WJ, Shen JG, Choi SH, Noh SH: Early postoperative intraperitoneal chemotherapy following cytoreductive surgery in patients with very advanced gastric cancer. Ann Surg Oncol 2007, 14:61-68.

29. Heise K, Bertran E, Andia ME, Ferreccio C: Incidence and survival of stomach cancer in a high-risk population of Chile. World J Gastroenterol 2009, 15:1854-1862.

30. Glehen O, Schreiber V, Cotte E, Sayag-Beaujard AC, Osinsky D, Freyer G, Francois $Y$, Vignal J, Gilly FN: Cytoreductive surgery and intraperitoneal chemohyperthermia for peritoneal carcinomatosis arising from gastric cancer. Arch Surg 2004, 139:20-26.

31. Yonemura Y, Kawamura T, Bandou E, Takahashi S, Sawa T, Matsuki N: Treatment of peritoneal dissemination from gastric cancer by peritonectomy and chemohyperthermic peritoneal perfusion. $\mathrm{Br}$ I Surg 2005, 92:370-375.

32. Yang XJ, Huang $C Q$, Suo T, Mei $\sqcup$, Yang GL, Cheng FL, Zhou YF, Xiong B, Yonemura Y, Li Y: Cytoreductive surgery and hyperthermic intraperitoneal chemotherapy improves survival of patients with peritoneal carcinomatosis from gastric cancer: final results of a phase III randomized clinical trial. Ann Surg Oncol 2011, 18:1575-1581.

33. Yan TD, Black D, Sugarbaker PH, Zhu J, Yonemura Y, Petrou G, Morris DL: A systematic review and meta-analysis of the randomized controlled trials on adjuvant intraperitoneal chemotherapy for resectable gastric cancer. Ann Surg Oncol 2007, 14:2702-2713.

34. Sierzega M, Kolodziejczyk P, Kulig J: Impact of anastomotic leakage on long-term survival after total gastrectomy for carcinoma of the stomach. Br J Surg 2010, 97:1035-1042.

35. Yoo HM, Lee HH, Shim JH, Jeon HM, Park CH, Song KY: Negative impact of leakage on survival of patients undergoing curative resection for advanced gastric cancer. J Surg Oncol 2011, 104:734-740.

36. Kubota T, Hiki N, Sano T, Nomura S, Nunobe S, Kumagai K, Aikou S, Watanabe R, Kosuga T, Yamaguchi T: Prognostic significance of complications after curative surgery for gastric cancer. Ann Surg Oncol 2014, 21:891-898.

37. Tokunaga M, Tanizawa Y, Bando E, Kawamura T, Terashima M: Poor survival rate in patients with postoperative intra-abdominal infectious complications following curative gastrectomy for gastric cancer. Ann Surg Oncol 2013, 20:1575-1583.

38. Li QG, Li P, Tang D, Chen J, Wang DR: Impact of postoperative complications on long-term survival after radical resection for gastric cancer. World J Gastroenterol 2013, 19:4060-4065.

\section{Submit your next manuscript to BioMed Central and take full advantage of:}

- Convenient online submission

- Thorough peer review

- No space constraints or color figure charges

- Immediate publication on acceptance

- Inclusion in PubMed, CAS, Scopus and Google Scholar

- Research which is freely available for redistribution

Submit your manuscript at www.biomedcentral.com/submit 